\title{
PERCEPÇÃO AMBIENTAL DA POPULAÇÃO SOBRE A ARBORIZAÇÃO URBANA NA CIDADE BARRA BONITA - SP
}

\author{
ENVIRONMENTAL PERCEPTION OF THE POPULATION ABOUT THE \\ URBAN AFFORESTATION IN BARRA BONITA - SP
}

Guilherme Munhoz Guerreiro ${ }^{1}$, Bianca Cristina Costa Gêa ${ }^{2}$, Marcos Vinicius Bohrer Monteiro Siqueira ${ }^{3}$

\section{RESUMO}

A matriz urbana é composta por diversos aspectos que avaliam o bem-estar da sociedade, entre esses, a arborização possui destaque no ordenamento territorial e na qualidade de vida da população; ao mesmo tempo sofre intempéries pela falta de gestão e de planejamento. As diferentes formas de percepção relacionadas à degradação do meio ambiente e aos conflitos gerados, suscitam compreensões e sentimentos que acabam por determinar outra realidade. A percepção ambiental da arborização urbana se reflete junto à expansão demográfica a partir da ausência de ligação entre natureza e cidade. A partir de um questionário semiestruturado, objetivou-se realizar uma análise com abrangência quantitativa e qualitativa da percepção ambiental com 127 moradores de quatro bairros da cidade de Barra Bonita, estado de São Paulo, Brasil. Os dados obtidos e analisados indicaram que os moradores possuem boa percepção ambiental, sendo que $63,78 \%$ dos entrevistados disseram conhecer o tema relacionado a cobertura de arborização $; 50 \%$ dos moradores classificaram a cidade como pouco arborizada, apontando e reconhecendo a importância de realizar a adequação dessa questão sob aspectos como sombreamento e melhora de temperatura, destacando estarem dispostos a contribuir de modo financeiro bem como no planejamento, manutenção e conservação da arborização, para que se possam realizar melhorias necessárias.

Palavras-chave: Flora Urbana; Planejamento urbano; Políticas públicas; Qualidade de vida.

\begin{abstract}
The urban matrix is composed by several aspects that evaluate the welfare of society, among them, the urban afforestation has prominence in the territorial planning and quality of life of the population. At the same time, it suffers from the lack of management and planning. The different forms of perception related to environmental degradation and the conflicts generated raise understandings and feelings that eventually determine another reality. The environmental perception of urban afforestation is reflected along the demographic expansion from the lack of connection between nature and city. Based on a semistructured questionnaire, the objective of this study was to conduct a qualitative and quantitative analysis about the environmental perception of 127 residents of four neighborhoods in the city of Barra Bonita, State of São Paulo. It was noted that the interviewees have good environmental perception, and $63.78 \%$ of respondents said they know the topic related to urban afforestation, $50 \%$ of the residents classified the city as poorly forested, pointing out and recognizing the importance of making the adequacy of this area, regarding shadow and temperature improving, highlighting their willingness to contribute financially, as well as, in the planning, maintenance and conservation of the urban afforestation.
\end{abstract}

Keywords: Urban flora; Urban planning; Public policy; Quality of life.

Recebido em 15.11.2019 e aceito em 02.03.2020

1 Eng. Ambiental e Sanitária. Universidade do Sagrado Coração. Bauru/SP. Email: guimunhooz@hotmail.com

2 Eng. Agronômica. Universidade do Sagrado Coração. Bauru/SP. Email: biaccgea@hotmail.com

3 Eng. Biotecnológica. Doutor em Ecologia Aplicada. Docente na Universidade Estadual de Minas Gerais - campus Frutal.

Frutal/MG. E-mail: mvbsiqueira@gmail.com 


\section{INTRODUÇÃO}

No Brasil, arborização urbana ainda é um tema novo. Apesar da importância milenar dos espaços verdes dentro das cidades, estima-se que sua atividade se tenha iniciado há pouco mais de 120 anos. Devido à importância desse tema, é necessário que ocorra o envolvimento dos cidadãos e administrações públicas, onde cada um deve cumprir o seu papel, exigindo junto ao poder público, que a arborização urbana desempenhe uma função plena de mantenedora do meio ambiente (BRASIL, 1988; SOUZA et al., 2017).

O avanço da industrialização juntamente com o aumento na concentração de pessoas nas cidades brasileiras em busca de emprego favoreceram o crescimento desordenado e sem planejamento das cidades, uma vez que a ocupação irregular dos solos, a exploração excessiva dos recursos naturais, a introdução de espécies invasoras, poluição generalizada, intensificação de enchentes, entre outros, geraram conflitos diretos entre as áreas construídas e vegetadas.

Esses fatores, a partir do momento em que afetam o ambiente, evidenciam a necessidade de um planejamento cada vez mais minucioso para com a ocupação do meio urbano, que considere a arborização urbana como um ponto de alta relevância. Nesse sentido, quando planejada de forma correta, a arborização urbana pode diminuir os impactos que essas interferências têm causado na população (SUFIA; SOUZA; SIQUEIRA, 2019).

Para definir com maior clareza tal abordagem, Miller (1997) caracteriza arborização urbana como "conjunto de toda a vegetação arbórea e suas associações dentro e ao redor das cidades, desde pequenos núcleos urbanos até as grandes regiões metropolitanas" e, neste, inclui as árvores de ruas, avenidas, praças, parques, unidades de conservação, áreas de preservação, espaços públicos ou privados, remanescentes de ecossistemas naturais ou plantados. No perímetro urbano, a arborização está relacionada a diversos benefícios, tais como melhorias no equilíbrio edáfico e microclimático, visto que absorvem radiação nos processos biológicos e proporcionam sombra e umidade à população; redução da poluição sonora e da velocidade dos ventos, que auxiliam na manutenção de diferentes espécies de aves, servindo de ponto de refúgio ou nidificação; melhorando a estética das ruas e, portanto, melhorando a qualidade de vida da população, entre outros (CABRAL, 2013).

Entretanto, a presença arbórea em áreas urbanas demanda atenção. Batista et al. (2013) ressaltam que se não houver conhecimento da importância da arborização urbana pela população, os pontos negativos podem prevalecer, como nos períodos chuvosos, ou quando as árvores estão dispostas em conflitos diretos com os demais ambientes da zona urbana. Entre esses conflitos pode-se apontar a fiação elétrica e telefônica, devido à inferência na mobilidade urbana e de trânsito, danos à pavimentação e de enraizamento descontrolado nas 
calçadas e vias públicas, na geração de resíduos que podem ser provenientes do acúmulo das folhas e pela sujeira gerada por aves que usam as árvores para o pouso.

A inter-relação entre os atores sociais e o meio ambiente necessita de uma avaliação que abranja a compreensão e percepção dessa arborização, observando a forma como o homem interpreta a adaptação da realidade em que vive, e como este pode contribuir com análises e instrumentos de planejamento e gestão das áreas verdes nas cidades (BONAMETTI, 2003).

Nesse sentido, o desenvolvimento da capacidade de percepção, constitui hoje, motivo para a avaliação de muitos estudos sobre a arborização urbana por todo o país (MELAZO, 2005). A percepção ambiental tem auxiliado na compreensão das expectativas, satisfações e insatisfações das populações no tocante ao seu meio e aos elementos relacionados à qualidade de vida e bem estar social. Isto é, compreender essa percepção auxilia o entendimento do homem com relação ao ambiente e fatores que o cercam e o influenciam, bem como na geração de informações relevantes para uma gestão ambiental da cidade, fornecendo dados para a elaboração de projetos de educação ambiental e implementação de políticas públicas sustentáveis nas cidades (PERIOTTO et al., 2016).

Visto que não há na literatura estudos realizados junto à população de Barra Bonita/SP sobre a percepção da arborização urbana, o presente trabalho teve como objetivo analisar a percepção ambiental dos moradores de quatro bairros da cidade. A contribuição deste com a gestão pública, auxiliará na elaboração de políticas de sensibilização e conscientização da população, principalmente na educação ambiental para os habitantes, assim como fornecerá elementos à base de dados para a adoção de ferramentas e boas práticas no que tange a arborização urbana da cidade de Barra Bonita, servindo como instrumento para promoção da melhora nos aspectos tangentes ao tema.

\section{MATERIAL E MÉTODOS}

O município de Barra Bonita, estado de São Paulo (Figura 1), está localizada entre as

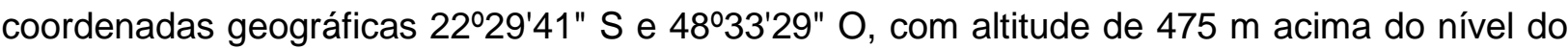
mar. Sua população foi estimada em 36.127 habitantes em 2018, possuindo uma área de $150,121 \mathrm{~km}^{2}$, cujo clima de ocorrência classificado segundo Köppen, é do tipo Aw, ou seja, clima tropical, com relevo ondulado e solo de terra roxa (IBGE, 2019).

Quatro bairros foram selecionados para o estudo, sendo eles: o Jardim Nova Barra, CDHU/COAB, Jardim dos Ypês e Residencial da Colina, fundados nos anos de 1978, 1993/1979, 2002 e 1999, respectivamente. A escolha desses bairros se baseou em aspectos quantitativos com relação à presença de árvores nesses locais, aliada à grande distância que 
apresentavam um do outro, fator que auxilia na variabilidade da presença arbórea, ainda dentro do mesmo município. A idade dos bairros em estudo também foi determinante na escolha, uma vez que bairros novos e antigos foram selecionados, tomando-se como exemplo o Jardim dos Ypês, com menos de 20 anos, e o Jardim Nova Barra, como dos mais antigos, já ultrapassando os 40 anos. As vias e imóveis selecionados para compor a área de estudo de cada bairro foram escolhidos de forma aleatória, bem como os entrevistados. Procurou-se entrevistar pelo menos um morador por rua, de cada bairro, de modo a englobar toda a área dos quatro bairros.

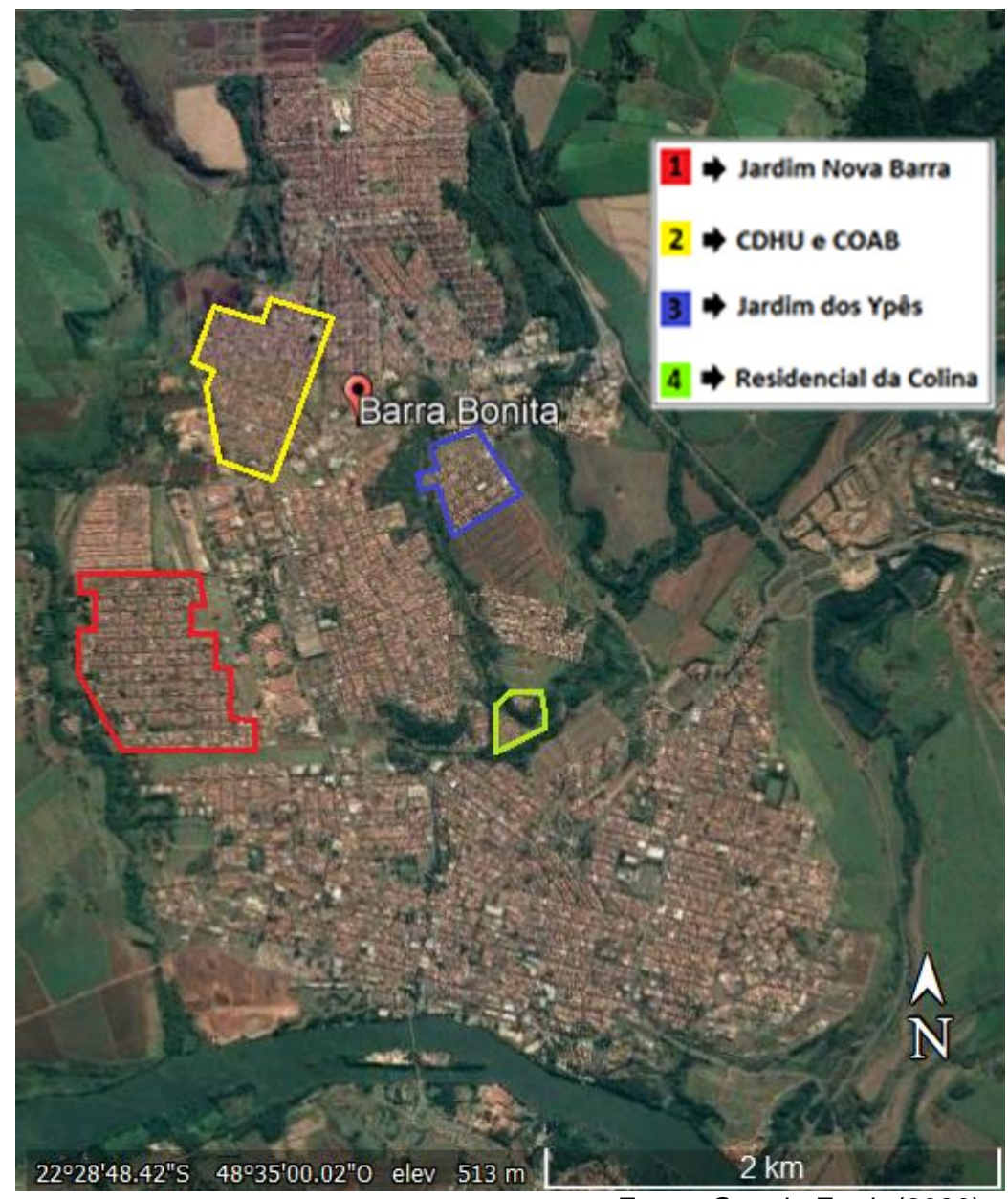

Fonte: Google Earth (2020)

Figura 1. localização dos bairros selecionados para a pesquisa na cidade de Barra Bonita/SP/Brasil Figure 1. Location of the selected neighborhoods for the research in the city of Barra Bonita/SP/Brazil.

A idade do morador respondente foi o critério adotado para a escolha dos indivíduos, que deveriam ter no mínimo 18 anos. Para mensurar a percepção ambiental da arborização urbana dos moradores, sua inter-relação e grau de expectativa e satisfação, coletaram-se os dados durante o primeiro semestre de 2018, com o auxílio de um formulário semiestruturado, composto por 17 questões abertas e fechadas (Figura 2). As questões foram lidas pelo entrevistador e explicadas ao entrevistado quando necessário. Não foram fornecidos exemplos, nem se induziu de qualquer forma os entrevistados, para que as respostas não fossem 
influenciadas. A coleta de dados foi baseada nos estudos de Santos et al. (2018), Sufia, Souza e Siqueira (2019) e Almeida, Gêa e Siqueira (2019).

Rua/n./bairro:

1. Sexo: (1) Feminino ( ) Masculino

2. Idade:

3. Qual é seu grau de escolaridade?

1.) Não alfabetizado

1.) Ensino fundamental incompleto

(1) Ensino médio incompleto

1.) Ensino superior incompleto

(1) Ensino fundamental completo

(u) Ensino médio completo

1.) Ensino superior completo

(n) Curso técnico

4. Tipo de estabelecimento

(u) Residencial próprio

(1) Comercial próprio

(u) Residencial cedido/emprestado

(1.) Residencial alugado

(.) Comercial alugado

5. Você sabe o que é Arborização Urbana?

( ) Sim ( ) Não

Caso não, pular pra 7

6. O que você entende por arborização urbana?

(1)) Árvore no quintal

(.) Árvore nas calçadas

(1) Árvore nas praças

1.) Outras formas:

7. Como você classifica a arborização urbana de sua rua?

(1) Não arborizado

(1.) Pouco arborizada

(1) Razoavelmente arborizada

(.) Muito arborizada

8. Quais as vantagens que você observa na arborização urbana?

1.) Sombra

(1) Preservação da biodiversidade

(1.) Redução do calor

(1) Beleza estética

1.) Outros:

9. Quais as desvantagens que você observa na arborização urbana?

(1) Sujeira nas ruas e calçadas

(1) Sujeira provocada pelos pássaros

(1) Problema nas calçadas

(1.) Problema com a rede elétrica ou telefônica

(1) Nenhuma

() Outras formas
10. Em sua opinião, quem é responsável pela arborização urbana?

\section{(.) População}

(1)) Prefeitura

(1) Prefeitura/População

(1) Outros:

11. Você colabora com a arborização urbana do seu bairro?

(1) $\operatorname{Sim}$

(1) Não

Caso NÃO, ir para questão 13

12. De qual forma você colabora?

(u) Fazendo manutenção e podando

(1) Plantando árvores

(u) Serviços comunitários

(1) Não danificando

(n) Outras formas:

13. O que poderia ser feito para melhorar a arborização de seu bairro?

(1.) Plantar mais árvores

(.) Fazer manutenção e realizar podas de forma adequada e em época correta

(w) Realizar um trabalho de conscientização ecológica sobre arborização

(.) Outras formas:

14. Você apoiaria uma lei municipal que regulamentasse a arborização urban em Barra Bonita?

(1) $\operatorname{Sim}$

(1) Não

15. Você estaria disposto a contribui financeiramente para arborização de sua rua?

(n) Sim

(u) Não

16. Por que você não esta disposto a contribuir financeiramente para a arborização urbana?

17. Você gostaria de receber uma muda de árvore para plantar e cuidar na calçada de sua residência?

(1) $\operatorname{Sim}$

(.) Não

Se não por quê?

Fonte: Adaptado de Silva Filho (2002)

Figura 2. Ficha de Inventário para cadastro de indivíduos utilizada no levantamento das árvores dos bairros Jardim Nova Barra, CDHU e COAB, Jardim dos Ypês e Residencial da Colina, da cidade de Barra Bonita/SP/Brasil

Figure 2. Inventory form for registration of individuals used to survey trees in the neighborhoods of Jardim Nova Barra, CDHU and COAB, Jardim dos Ypês and Residencial da Colina, of the city of Barra Bonita/SP/Brazil 
Cada formulário foi preenchido a partir da entrevista com um responsável pela moradia, totalizando 127 entrevistados nos quatro bairros, sendo, 61 entrevistados da Companhia de Desenvolvimento Habitacional e Urbano do Estado de São Paulo (CDHU), 44 do Jardim Nova Barra, 12 do Residencial da Colina e 10 do Jardim dos Ypês. A amostragem correspondeu a $0,37 \%$ do total de residentes urbanos da cidade de Barra Bonita, onde, conforme último censo realizado pelo IBGE, a população era de 34,507 mil habitantes (IBGE, 2019). Além do número de entrevistados ter se aproximado dos desenvolvidos em outros levantamentos do gênero (MAIA et al., 2017; SANTOS et al., 2018), é preciso ser registrado que os questionários foram aplicados dentro do perímetro urbano da cidade, em horário comercial durante a semana, período que a grande maioria dos moradores se encontram nos seus locais de trabalho. Após a aplicação do formulário em campo, os dados foram tabulados e armazenados em uma planilha eletrônica do Software Microsoft Excel 2010, tendo sido obtidas as frequências absolutas para as diferentes questões.

\section{RESULTADOS E DISCUSSÃO}

\section{Perfil e aspectos amostrais da população}

Foram entrevistados 127 moradores, sendo $51 \%$ foram do sexo masculino e $49 \%$ feminino. A análise do perfil dos entrevistados demonstrou que $27 \%$ possuíam idade entre 40 e 59 anos, $18 \%$ entre 60 e 69 anos, $17 \%$ entre 30 e 39 anos, $11 \%$ entre 18 e 29 anos e, finalmente, $7 \%$, entre 70 e 90 anos.

Para uma avaliação distribuída por localidade, a maior concentração amostral ocorreu no CDHU-COAB, com $48 \%$ dos entrevistados, seguido do Jardim Nova Barra com $34,6 \%$ dos indivíduos, Residencial da Colina e Jardim dos Ypês com 9,4\% e 7,9\%, respectivamente (Figura 3).

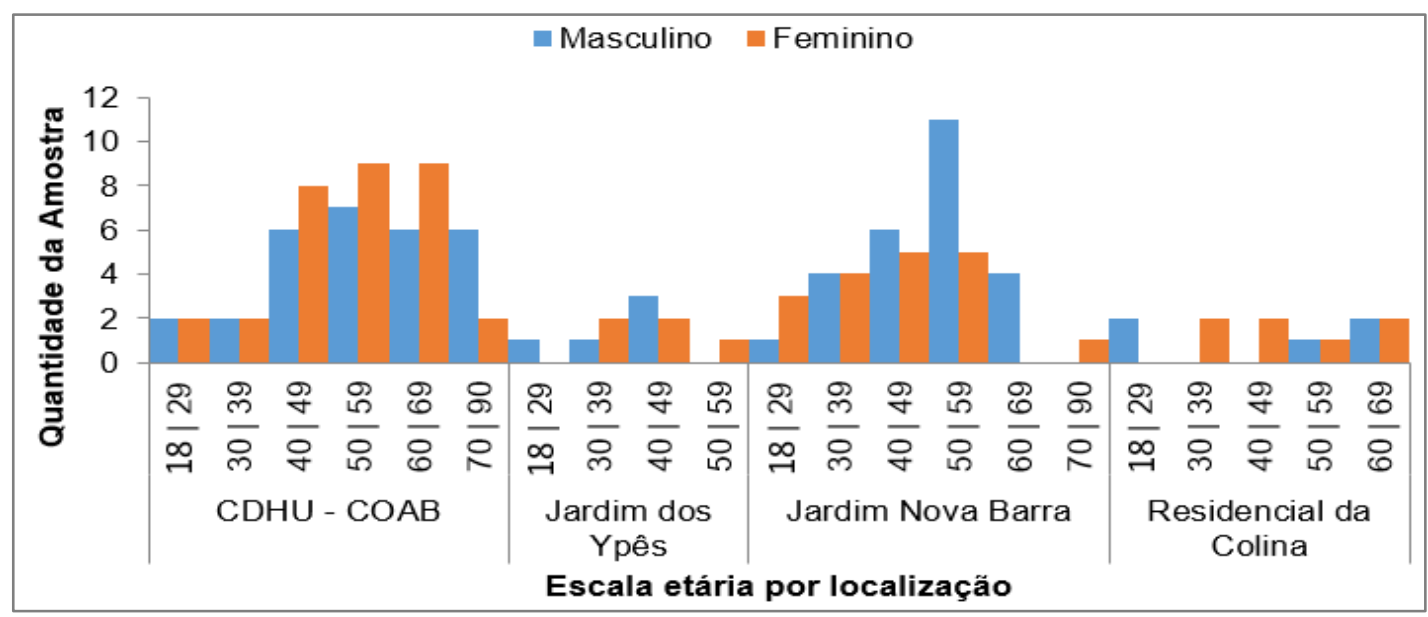

Figura 3. Distribuição etária por localidade e sexo da amostra na cidade de Barra Bonita/SP/Brasil

Figure 3. Age distribution by location and gender of the sample in the city of Barra Bonita/SP/Brazil 
Ao analisar o grau de escolaridade dos entrevistados, observou-se que $8,6 \%$ possuem o ensino superior completo e 5,5\% superior incompleto; $3,9 \%$ possuem curso técnico, $24,4 \%$ apresentam ensino médio completo e 6,3\% ensino médio incompleto; $11,02 \%$ possui ensino fundamental completo e 33,07\% ensino fundamental incompleto; e 5,5\% são aletrados. Esses dados são interessantes pois foi possível identificar o perfil dos entrevistados, e desta forma possibilitar uma correlação com o nível de instrução e a percepção da arborização urbana pelos moradores. A falta ou o baixo nível de escolaridade não estão diretamente associados à percepção da arborização, no entanto, podem influenciar certo grau de dificuldade dos entrevistados em responder questões mais complexas (ROPPA et al., 2007).

Com relação ao tipo de residência, $88 \%$ dos entrevistados declararam possuir residência própria, enquanto apenas $8 \%, 3 \%$ e 1\%, declararam possuir imóvel residencial alugado, imóvel comercial próprio e imóvel comercial alugado, respectivamente (Figura 4)

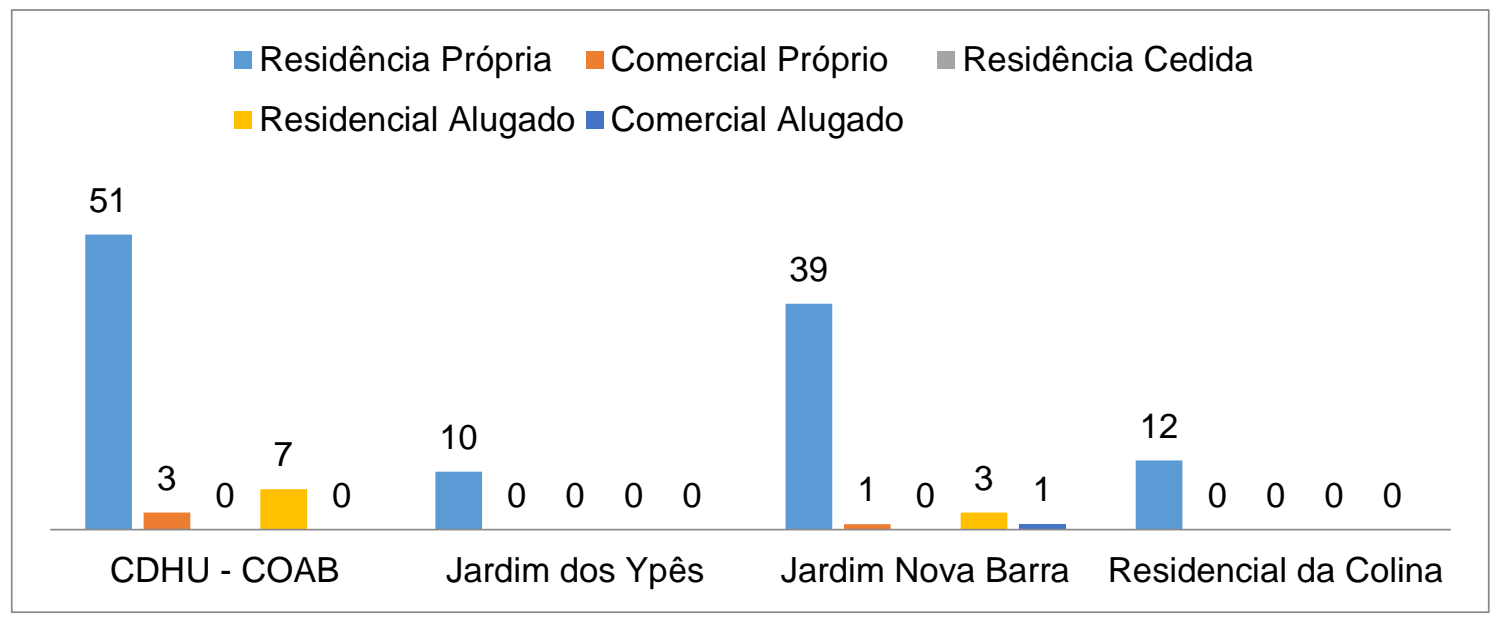

Figura 4. Tipo de habitação da amostra na cidade de Barra Bonita/SP/Brasil

Figure 4. Type of housing of the sample in the city of Barra Bonita/SP/Brazil

\section{Avaliação da percepção ambiental dos entrevistados}

Quando questionados se os entrevistados sabiam do que se tratava "arborização urbana", 63,78\% responderam que sim, e a parcela restante respondeu que não tinha conhecimentos a respeito. Neste caso, o questionário permitia ao entrevistado responder apenas "sim" ou "não". Estudo realizado por Almeida, Gêa e Siqueira (2019) na cidade de Arealva/SP, demonstrou que $79,13 \%$ dos entrevistados disseram conhecer a respeito do tema, contra $20,87 \%$ que declararam não possuir conhecimento.

Foi então solicitada ao entrevistado a definição de arborização urbana, e 45 pessoas das entrevistadas responderam como sendo "as árvores presentes nas calçadas", o que correspondeu a $35,4 \%$ dos entrevistados. Os participantes restantes relataram a respeito das "árvores nas praças, quintal e outras", o que correspondeu, respectivamente, a 29,9\% (38 
pessoas), $16,5 \%$ (21 pessoas) e 1,6\% (2 pessoas) dos entrevistados, totalizando $83,4 \%$ ou 106 entrevistados (Figura 5).

$\mathrm{Na}$ cidade de Tefé-AM, Santos et al. (2018), mostraram que $42 \%$ dos entrevistados conceituaram arborização urbana como sendo "as árvores presentes na cidade", $21 \%$ citaram "as árvores das calçadas", 16\% "as árvores nas ruas e nas praças", e apenas 5\% relataram o termo estar relacionado às "árvores nos bairros". Pode-se verificar que os moradores da cidade de Barra Bonita apresentaram boa percepção ambiental quando relacionado à definição da arborização urbana, uma vez que, segundo Araújo et al. (2010), este termo pode ser entendido como toda a vegetação arbórea, que ocupa espaços livres públicos e privados de uma cidade.

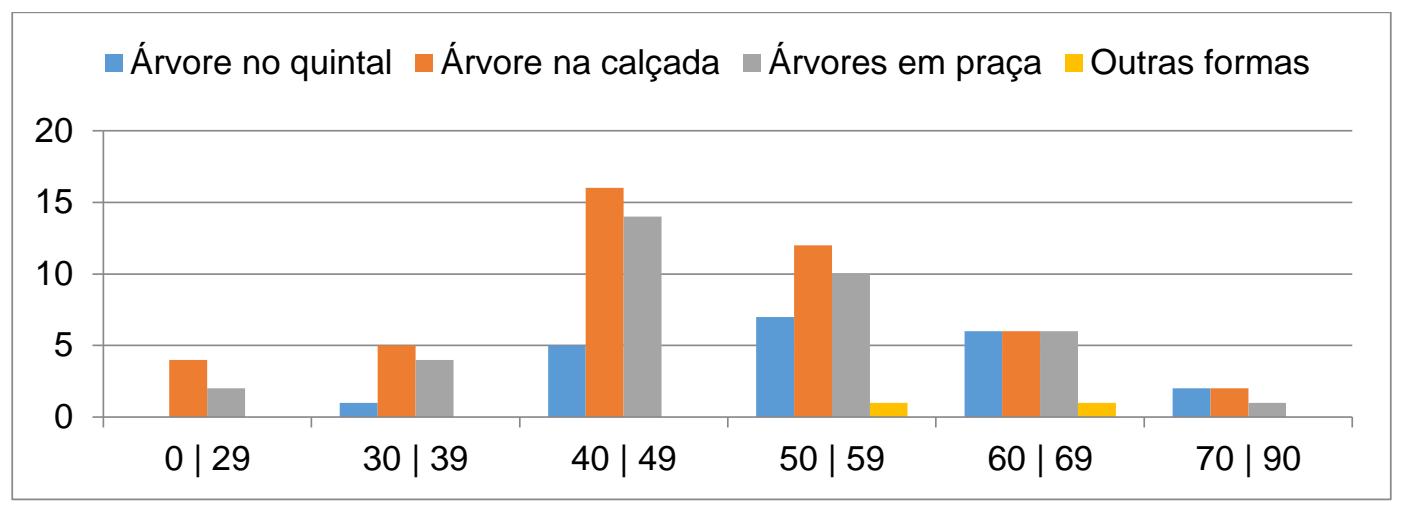

Figura 5. Grau de entendimento da Arborização Urbana da amostra na cidade de Barra Bonita/SP Figure 5. Degree of understanding of urban afforestation of the sample in the city of Barra Bonita/SP

Em seguida foi solicitado aos entrevistados que quantificassem a arborização nos ambientes que circundam seu cotidiano. Na sua grande maioria, 50,4\% (64 pessoas) entendem que seu meio está pouco arborizado, sinalizando a necessidade de ações e planejamento para adequar essa situação; 32,3\% (41 pessoas) consideram razoavelmente arborizado e 16,5\% (21 pessoas) muito arborizado. Dados obtidos por Souza et al. (2018), na cidade de Pombal/PA, demonstraram que $62 \%$ dos entrevistados classificaram a cidade como razoavelmente arborizada, $36 \%$ como pouco arborizada e os $2 \%$ restantes como muito arborizada. Segundo Silva, Santos e Oliveira (2016) a quantidade mínima preconizada pela Organização Mundial da Saúde (OMS) é de $12 \mathrm{~m}^{2}$ de área verde por habitante, e a ideal seria de $36 \mathrm{~m}^{2}$, algo em torno de três árvores, por habitante. No entanto, a cidade de Barra Bonita possui média de 1,5 árvore por habitante, o que revela que a cidade apresenta apenas metade do índice recomendado, embora seja, ainda, superior a capital paulista, onde o índice se posiciona em 0,6 árvore por habitante (BUCKERIDGE, 2015).

Constatado que existe pouca arborização nos bairros avaliados, foi questionado aos entrevistados quais seriam as vantagens que a arborização urbana prestaria como serviço ambiental para os moradores. Dentre as opções destacadas e com a possibilidade de 
selecionar mais de uma alternativa, os entrevistados destacaram seis vantagens principais: $65,3 \%$ dos entrevistados relataram que o fato de as árvores fornecerem sombra é muito relevante; 46,4\% citaram a redução de calor; 30,7\% mencionaram a preservação da biodiversidade; $14,2 \%$ destacaram a beleza estética e 3,9\% apontaram outros fatores. Em São José de Piranhas - PB, constatou-se que $32 \%$ dos entrevistados referiram como principal vantagem o sombreamento, seguido da presença de flores, com $2 \%$ dos entrevistados (LACERDA et al., 2010).

Com relação às desvantagens, 40,9\% dos moradores indicaram não haver problemas relacionados à arborização urbana, no entanto $29,9 \%$ apontaram a sujeira nas ruas e calçadas causadas por folhas como a principal desvantagem, seguido de problemas nas calçadas e redes elétricas, com $16,5 \%$ e 5,5\% respectivamente, sujeira ocasionada pelos pássaros que usam as árvores como pousio ou nidificação (1,5\%) e outros (8,6\%). No município de Paragominas - PA, Oliveira et al. (2017) observaram que mais de $91 \%$ dos moradores consideraram que não existem desvantagens, 4,95\% relataram a sujeira de ruas e calçadas e os demais itens como sujeira provocada pelos pássaros; redução da iluminação pública, problemas na rede elétrica e complicações nas calçadas correspondeu à opinião de $4,05 \%$ dos entrevistados, o que corrobora com os resultados encontrados no presente estudo.

Nesse sentido, a questão referente à responsabilidade da gestão e manejo da flora urbana, os entrevistados, em sua grande maioria apontaram que os deveres e obrigações devem ser compartilhados entre a população e a Prefeitura (73,2\%). Segundo Almeida, Fernandes e Souto (2019), 85\% dos entrevistados do distrito de lara, no Ceará, relataram que a arborização urbana é de responsabilidade da prefeitura, enquanto 33\% disseram ser a população a principal responsável. Contudo, conforme estabelece o artigo 225 da Constituição Federal de 1988, é dever do poder público e da população, não apenas defendê-lo, mas também preservá-lo (BRASIL, 1988). Com essas informações, foi questionado seguidamente se o entrevistado colaborava com a flora urbana da cidade, sendo que $62,2 \%$ indicaram que sim, e 27,6\% que não. Ao aprofundar essa questão, foi solicitado aos moradores que respondessem qual seria a forma de colaboração. Para 33,1\% dos entrevistados o plantio de árvores seria a melhor maneira de colaboração, e para 31,5\% a manutenção seria a melhor forma de auxílio. Vale destacar que o simples fato de não danificar as árvores através de injúrias, para cerca de $15 \%$ dos entrevistados já era uma forma de colaborar para a arborização. Sufia, Souza e Siqueira (2019), em um estudo realizado em dois bairros da cidade de Bauru-SP, observaram que $42 \%$ dos entrevistados afirmaram colaborar com a arborização do bairro Parque Santa Edwirges, enquanto no bairro Jardim Europa, 72\% dos participantes disseram que contribuem para manutenção da arborização. Já com relação a forma com que 
são realizadas essas manutenções, pode-se destacar a realização de plantios (39\%), manutenção e poda (37\%) (SUFIA; SOUZA; SIQUEIRA, 2019).

Foi questionado aos entrevistados, o que poderia ser feito para melhorar a situação da arborização urbana na cidade, e seguindo a tendência dos dados anteriores, o ponto de destaque foi novamente a manutenção dos indivíduos arbóreos (49,6\%). Ficou evidenciado que realizar uma manutenção adequada, efetuando podas de forma correta e adequada para cada espécie bem como realizar o plantio de mais árvores $(44,1 \%)$ são as principais ações que na percepção dos moradores, pode contribuir para a melhoria dos serviços prestados à flora urbana, agregando assim valor à qualidade de vida dos moradores. Em Arealva/SP, os entrevistados relataram que a melhor forma de melhorar a arborização da cidade seria por meio da manutenção, com podas adequadas $(49,6 \%)$, plantio de novas árvores $(31,3 \%)$ bem como trabalhos de conscientização ecológica (19,1\%) (ALMEIDA; GÊA; SIQUEIRA, 2019). Zen e Biondi (2014) em uma análise sobre a percepção dos entrevistados quanto à colaboração na "manutenção das mudas de árvores", observaram que 40,5\% dos entrevistados realizam a manutenção de alguma maneira, seja regando as mudas, roçando ao redor das mesmas, ou recolocando tutores (piquetes introduzidos junto ao plantio da muda que auxiliam no seu desenvolvimento ereto, permitindo melhor formação da copa) arrancados por vândalos. Dentre esses, 28\% afirmam plantar novas mudas, $21 \%$ contribuem na manutenção e em podas corretas, $3 \%$ colaboram ao não danificar, e 2\% realizam serviços comunitários.

Com base no compartilhamento de responsabilidades do poder público local e habitantes em relação à arborização urbana, questionou-se o conhecimento dos moradores sobre a lei municipal para a regulamentação da Arborização Urbana da cidade de Barra Bonita. Aproximadamente, 62\% assumiram conhecer a lei, observando nesta, a necessidade de ser respeitada; $17,3 \%$ desconhecem a legislação e os demais não responderam à questão. Em Tefé, Amazonas, Maia et al. (2017) relataram que 93\% dos entrevistados afirmaram que apoiariam uma lei municipal, que regulamentasse a arborização urbana no município.

Outro ponto que a presente pesquisa apurou foi se os entrevistados estariam dispostos a contribuir financeiramente para o manejo e manutenção da arborização. Nesse aspecto, desconsiderando-se imposição ou suposição de valores, 71 entrevistados, representando 55,9\%, indicaram que participariam, mas $23,6 \%$ destacaram que não realizariam nenhuma contribuição financeira, pelo fato de os moradores já realizarem de certa forma pagamento através do Imposto Predial Territorial Urbano (IPTU) da cidade. Malavasi e Malavasi (2001) em pesquisa realizada no Paraná, encontrou resultados semelhantes ao apontar que $59 \%$ dos entrevistados que declararam ser favoráveis a contribuir financeiramente para a manutenção da arborização urbana. Lacerda et al. (2010) realizaram uma pesquisa em São José de Piranhas-PB, e ao questionar os entrevistados sobre a possibilidade de 
contribuírem financeiramente para a manutenção da arborização urbana, a maioria respondeu que não contribuiria (83,5\%).

Finalmente foi questionado se o entrevistado aceitaria uma muda de árvore, para ser plantada e cuidada na calçada de sua residência, e 68,5\% responderam positivamente, concordando em receber uma muda. Porém 30,7\% disseram que não aceitariam, dado que a calçada já tinha árvores plantadas. Em Cananéia - SP, Maistro e Ferraz (2018) mostraram que, caso a muda fosse doada para plantio na calçada, $48,8 \%$ dos entrevistados plantariam as mudas, contudo $20 \%$ alegaram que não plantariam, uma vez que a residência é alugada; $16,3 \%$ atribuíram ao risco de a árvore poder gerar conflitos na fiação elétrica, e 15\% apontaram que a calçada seria muito estreita, inviabilizando o plantio de mudas. Segundo Soares, Alves e Targino (2017), arborizar não significa plantar árvores aleatoriamente em qualquer lugar, mas seguir normas e diretrizes legais.

\section{CONCLUSÕES}

Os moradores entrevistados de Barra Bonita/SP possuem uma boa percepção ambiental sobre o tema da arborização urbana, indicando ter conhecimento sobre a questão. Vale destacar que, $50 \%$ dos moradores classificaram a cidade como tendo pouca cobertura de arborização, apontando e reconhecendo a importância de realizar sua adequação. Assim, uma parcela significativa dos moradores está disposta a contribuir para regulamentação, tanto na criação de uma lei municipal, quanto financeiramente no planejamento, manutenção e conservação da arborização urbana.

Espera-se que os dados obtidos signifiquem uma forma de contribuição para com a gestão pública, na elaboração de políticas de sensibilização e conscientização da população, principalmente na educação ambiental para os habitantes, assim como fornece elementos à base de dados para a adoção de ferramentas e boas práticas no que tange a arborização urbana da cidade de Barra Bonita, São Paulo, Brasil.

\section{AGRADECIMENTOS}

Gostaríamos de agradecer à Mirian Cury pelas correções textuais, ao José Tiago do Nascimento e ao Pedro Dario por algumas informações obtidas sobre Barra Bonita e aos anônimos revisores pelas melhorias no manuscrito. 


\section{REFERÊNCIAS}

ALMEIDA, C. G.; GÊA, B. C. C.; SIQUEIRA, M. V. B. M. Percepção ambiental da população sobre a arborização urbana do bairro centro no município de Arealva, São Paulo. Revista da Sociedade Brasileira de Arborização Urbana, Curitiba, v. 14, n. 3, p. 37-49, 2019.

ALMEIDA, E. P.; FERNANDES, S. P. S.; SOUTO, P. C. Arborização urbana na percepção da população do distrito de lara no Ceará. Revista da Sociedade Brasileira de Arborização Urbana, Curitiba, v. 14, n. 2, p. 16-30, 2019.

ARAÚJO, J. L. O.; ARAÚJO, A. C.; ARAÚJO, A. C. Percepção ambiental dos residentes do bairro Presidente Médici, em Campina Grande - PB, no tocante à arborização local, Revista da Sociedade Brasileira de Arborização Urbana, Piracicaba, v.5, n.2, p. 67-81, 2010.

BATISTA, F. A.; CHAVES, T. P.; FELISMINO, D. C.; DANTAS, I. C. Inventário quali-quantitativo da arborização urbana na cidade de Remígio, Paraíba. Revista de Biologia e Farmácia, Campina Grande, v. 9, n. 1, p. 70-83, 2013.

BONAMETTI, J. H. Arborização Urbana. Terra e Cultura, Londrina, n.36, p. 51-55, 2003.

BRASIL. Constituição da República Federativa do Brasil de 1988. Diário Oficial da União. 5 out. 1988.

BUCKERIDGE, M. Árvores urbanas em São Paulo: planejamento, economia e água. Estudos avançados, São Paulo, v. 29, n. 84, p. 85-101, 2015.

CABRAL, P. I. D. ARBORIZAÇÃO URBANA: Problemas e Benefícios. Revista On-Line IPOG, Goiania, v. 1, n. 6, 2013.

IBGE - Instituto de Geografia e Estatística. IBGE Cidades - Barra Bonita. Disponível em: https://cidades.ibge.gov.br/brasil/sp/barra-bonita. Acesso em: 06 fev. 2020.

LACERDA, N. P.; SOUTO, P. C.; DIAS, R. S; SOUTO, L. S.; SOUTO, J. S. Percepção dos residentes sobre a arborização da cidade de São José de Piranhas - PB. Revista da Sociedade Brasileira de Arborização Urbana, Piracicaba, v. 5, n. 4, p. 81-95, 2010.

MAIA, L. P. S. S.; OLIVEIRA, E. D.; SANTOS, M. O.; CELLA, W. Estudo da percepção ambiental sobre a arborização urbana no bairro fonte boa, Tefé-amazonas, Brasil. Revista da Sociedade Brasileira de Arborização Urbana, Piracicaba, v,12, n. 2, p. 48-61, 2017.

MAISTRO, A. P. S.; FERRAZ, M. V. Percepção dos moradores de Cananéia - SP sobre a arborização urbana do município. Revista Brasileira de Arborização Urbana, Piracicaba, v. 13, n. 1, p. 14-27, 2018.

MALAVASI, U. C; MALAVASI, M. M. Avaliação da arborização urbana pelos residentes estudo de caso em Mal. Cândido Rondon, Paraná, Ciência Florestal, Santa Maria, v.11, n.1, p.189-193, 2001.

MELAZO, G. C. Percepção ambiental e educação ambiental: uma reflexão sobre as relações interpessoais e ambientais no espaço urbano. Olhares \& Trilhas, Uberlândia, v. 6, n. 6, p. 4551, 2005. 
MILLER, R. W. Urban forestry: Planning and managing urban greenspaces (2nd ed.). Upper Saddle River, NJ: Prentice Hall, 1997, 512 p.

OLIVEIRA, V. P.; DIAS, J. G. S.; RIBEIRO, A. T.; OLIVEIRA, L. B. S.; MARIANO, M. O.; PINTO, D. S. A percepção da população sobre arborização em um conjunto habitacional no município de Paragominas - PA. Revista da Sociedade Brasileira de Arborização Urbana, Piracicaba, v. 12, n. 3, p. 27-36, 2017.

PERIOTTO, F.; PITUCO, M. M.; HELMANN, A. C.; SANTOS, T. O.; BORTOLOTTI, S. L. Análise da Arborização Urbana no município de Medianeira, Paraná. Revista da Sociedade Brasileira de Arborização Urbana, Piracicaba, v. 11, n. 2, p. 59-74, 2016.

ROPPA, C.; FALKENBERG, J. R.; STANGERLIN, D. M.; BRUN, F. G. K.; BRUN, E. J.; LONGHI, S. J. Diagnóstico da percepção dos moradores sobre a arborização urbana na vila Estação Colônia - Bairro Camobi, Santa Maria - RS. Revista da Sociedade Brasileira de Arborização Urbana, Piracicaba, v. 2, n. 2, p.11-30, 2007.

SANTOS, M. O.; MAIA, L. P. S. S.; OLIVEIRA, E. D.; SILVA NETO, J. C. A.; CELLA, W. Percepção ambiental sobre a arborização urbana no bairro Santa Tereza, Tefé, Amazonas, Brasil. Revista Ra'e Ga: o espaço geográfico em análise, Curitiba, v. 44, p. 231-241, 2018.

SILVA, A. D. P.; SANTOS, A. F.; OLIVEIRA, L. M. Índices de área verde e cobertura vegetal das praças públicas da cidade de Gurupi, TO. Floresta, Curitiba, v. 46, n. 3, p. 353 - 361, 2016.

SOARES, A. M. J.; ALVES, R. L. E; TARGINO, E. N. M. A. Acessibilidade na arborização urbana: percepção de deficientes visuais sobre a mobilidade em espaços públicos arborizados. Revista Brasileira de Arborização Urbana, Piracicaba, v. 12, n. 3, p. 51-65, 2017.

SOUZA, V. F. O.; SANTOS, G. L.; RODRIGUES, M. H. B. S.; BARROSO, R. F.; BARBOZA, J. B.; FERNANDES, A. V. F. Percepção sobre a qualidade da arborização urbana na cidade de Pombal, Paraíba. Revista Verde de Agroecologia e Desenvolvimento Sustentável, LOCAL, v. 13, n.3, p.343-347, 2018.

SOUZA, M. A. S.; SOUTO, P. C.; FERNANDES, S. P. S.; NEVES, A. A.; SOUTO, J. S. Percepção da população relacionada à arborização urbana de praças no centro da cidade de Patos-PB. Agropecuária Científica no Semiárido, Patos, v. 12, n. 4, p. 368-375, 2017.

SUFIA, M. C. S.; SOUZA, G. S.; SIQUEIRA, M. V. B. M. Percepção ambiental sobre arborização urbana em regiões distintas do município de Bauru - SP. Revista da Sociedade Brasileira de Arborização Urbana, Curitiba, v.13, n. 4, p. 15-28, 2019.

ZEN, L.; BIONDI, D. Análise da percepção da população em relação ao vandalismo na arborização urbana viária de Curitiba - PR. Revista da sociedade brasileira de Arborização Urbana, Piracicaba, v. 9, n. 3, p. 86-107, 2014. 